\title{
Article \\ Influence of Glucose on Candida albicans and the Relevance of the Complement FH-Binding Molecule Hgt1 in a Murine Model of Candidiasis
}

\author{
Verena Harpf ${ }^{1}$, Samyr Kenno ${ }^{1}{ }^{\mathbb{D}}$, Günter Rambach ${ }^{1} \mathbb{D}$, Verena Fleischer ${ }^{1}$, Nadia Parth ${ }^{1}$, \\ Christian X. Weichenberger $^{2}$, Peter Garred ${ }^{3}$, Silke Huber ${ }^{1}{ }^{\mathbb{D}}$, Cornelia Lass-Flörl ${ }^{1}{ }^{\mathbb{D}}$, Cornelia Speth ${ }^{1}$ \\ and Reinhard Würzner $1, *$ (D)
}

Citation: Harpf, V.; Kenno, S.; Rambach, G.; Fleischer, V.; Parth, N.; Weichenberger, C.X.; Garred, P.; Huber, S.; Lass-Flörl, C.; Speth, C.; et al. Influence of Glucose on Candida albicans and the Relevance of the Complement FH-Binding Molecule

Hgt1 in a Murine Model of

Candidiasis. Antibiotics 2022, 11, 257. https://doi.org/10.3390/ antibiotics 11020257

Academic Editor: Samir Jawhara

Received: 24 January 2022

Accepted: 14 February 2022

Published: 16 February 2022

Publisher's Note: MDPI stays neutral with regard to jurisdictional claims in published maps and institutional affiliations.

Copyright: (C) 2022 by the authors. Licensee MDPI, Basel, Switzerland. This article is an open access article distributed under the terms and conditions of the Creative Commons Attribution (CC BY) license (https:// creativecommons.org/licenses/by/ $4.0 /)$.
1 Institute of Hygiene and Medical Microbiology, Medical University of Innsbruck, 6020 Innsbruck, Austria; verena.harpf@i-med.ac.at (V.H.); samyr.kenno@uksh.de (S.K.); guenter.rambach@i-med.ac.at (G.R.); verena.fleischer@i-med.ac.at (V.F.); nadia.parth@i-med.ac.at (N.P.); silke.huber@i-med.ac.at (S.H.); cornelia.lass-floerl@i-med.ac.at (C.L.-F.); cornelia.speth@i-med.ac.at (C.S.)

2 Institute for Biomedicine (Affiliated to the University of Lübeck), Eurac Research, 39100 Bolzano, Italy; christian.weichenberger@eurac.edu

3 Laboratory of Molecular Medicine, Department of Clinical Immunology Section 7631, Rigshospitalet, Copenhagen University Hospital, 2200 Copenhagen N, Denmark; peter.garred@regionh.dk

* Correspondence: reinhard.wuerzner@i-med.ac.at; Tel.: +43-512-90030-70707

\begin{abstract}
Candidiasis is common in diabetic patients. Complement evasion is facilitated by binding complement factor $\mathrm{H}(\mathrm{FH})$. Since the expression of high-affinity glucose transporter 1 (Hgt1), a FH-binding molecule, is glucose-dependent, we aimed to study its relevance to the pathogenesis of Candida albicans. Euglycemic and diabetic mice were intravenously challenged with either Candida albicans lacking Hgt1 (hgt1-/-) or its parental strain (SN152). Survival and clinical status were monitored over 14 days. In vitro, Candida albicans strains were grown at different glucose concentrations, opsonized with human serum, and checked for $\mathrm{C} 3 \mathrm{~b} / \mathrm{iC} 3 \mathrm{~b}$ and $\mathrm{FH}$ deposition. Phagocytosis was studied by fluorescein isothiocyanate-labeled opsonized yeast cells incubated with granulocytes. The murine model demonstrated a significantly higher virulence of SN152 in diabetic mice and an overall increased lethality of mice challenged with hgt1-/-. In vitro lower phagocytosis and C3b/iC3b deposition and higher FH deposition were demonstrated for SN152 incubated at higher glucose concentrations, while there was no difference on hgt1-/- at physiological glucose concentrations. Despite $\mathrm{C} 3 \mathrm{~b} / \mathrm{iC} 3 \mathrm{~b}$ and $\mathrm{FH}$ deposition being glucose-dependent, this effect has a minor influence on phagocytosis. The absence of Hgt1 is diminishing this dependency on complement deposition, but it cannot be attributed to being beneficial in a murine model.
\end{abstract}

Keywords: Candida albicans; Hgt1; diabetes; complement; factor H; C3; murine model

\section{Introduction}

The complement system plays a central role in innate immunity, bridging the innate and the adaptive immune defense [1]. This complex system consists of over 40 proteins, soluble plasma factors, cell-associated regulator molecules, and receptors [2]. After an appropriate surface-bound or soluble pattern recognition receptor gets in contact with either pathogen-associated molecular patterns or foreign cellular structures such as cell debris or non-self-tissue, the activation starts within seconds. This activation can take place by three pathways, the classical (CP), the lectin (LP), and the alternative pathway (AP). Those three activation pathways merge in the enzymatic activation of $\mathrm{C} 3$, and subsequent cleavage of C5 [1]. The cleavage product C5b exhibits a binding site for C6, starting the formation of the terminal complement complex. The nonenzymatically sequentially activated C7, C8, and C9 adhere to C5b6 to form this complex, which can either exist in soluble form or produce a lytic pore as a membrane-attack complex (MAC) [1]. 
To avoid potentially harmful inflammation and adaptive immune response, Candida albicans, which is normally a commensal of the human body, has evolved several immune evasion strategies [3-9]. The complement evasion strategies can be divided into three patterns; firstly, the masking from recognition by the complement, secondly, cleavage and blocking of complement proteins, and thirdly, recruitment of complement regulators. The $\beta$-glucan layer of Candida albicans is masked by a sheath of mannan, therefore inhibiting the recognition by the alternative pathway [3]. The essential characters of the second pattern of the complement evasion are secreted aspartyl proteases (Saps) [4]. For the third, besides the masking from complement and the destruction or blockage of various complement proteins, Candida albicans recruits proteins, which normally regulate the complement system to avoid detrimental effects on endogenous cells. Although bound to either yeast cells or pseudohyphae, those regulators keep their functions. Factor $\mathrm{H}$ $(\mathrm{FH})$, the major regulator of the $\mathrm{AP}$, and its truncated form, factor-H-like protein 1 (FHL-1), are acquired by Candida albicans using four different proteins, namely phosphoglycerate mutase 1 (Gpm1) [5], pH-regulated antigen 1 (Pra1) [6], high affinity glucose transporter 1 (Hgt1) [7], and glycerol-3-phosphate dehydrogenase 2 (Gpd2) [8]. Bound FH exerts three effector functions; the protein competes with factor $\mathrm{B}$ (FB) for the binding of $\mathrm{C} 3 \mathrm{~b}$ and therefore inhibits the assembly of the AP C3- and C5-convertases [9]. Furthermore, $\mathrm{FH}$ accelerates the decay of the $\mathrm{C} 3$-and $\mathrm{C} 5$-convertases by displacing bound factor $\mathrm{Bb}$. Lastly, the acquisition of this regulator leads to ameliorated factor I (FI)-mediated cleavage and inactivation of $\mathrm{C} 3 \mathrm{~b}$, preventing its participation in the terminal complement pathway [2]. As an opportunistic pathogen, this species can cause mucosal and disseminated infections under certain circumstances such as iatrogenic immunosuppression, transplantation, antibiotic treatment, and untreated diabetes mellitus [10], providing the pathogen a huge basis to spread.

In particular, diabetes mellitus is a metabolic disorder characterized by elevated blood sugar; fasting ( $8 \mathrm{~h}$ without food intake) plasma glucose levels of $\geq 126 \mathrm{mg} / \mathrm{dL}$, or the 2-h plasma glucose level of $\geq 200 \mathrm{mg} / \mathrm{dL}$ [11], affect an estimated 463 million people in 2019 with increasing numbers due to sedentary living and high-energy dietary intake [12], especially type 2 diabetes [11]. Diabetes is linked to cardiovascular disease and alterations of the immune system, especially the cell-mediated immunity, affecting adherence, chemotaxis, phagocytosis, oxidative burst, and intracellular killing, which generates a higher susceptibility of diabetic patients to fungal and bacterial infections compared to euglycemic individuals [13]. Levels just below diabetic individuals are called prediabetes, which is linked to a higher risk of developing diabetes and cardiovascular disease [11].

Considering the higher susceptibility of diabetic patients to candidiasis and the glucose-dependent expression of the Candida albicans FH-binding molecule Hgt1, this study aimed to enlighten the relevance of this molecule, hyperglycemia, and the complement system on the pathogenesis of Candida albicans.

\section{Results}

\subsection{Absence of Hgt1 or C3 Increases the Virulence of Candida albicans in a Murine Model of Systemic Candidiasis}

Preceding research showed the relevance of Hgt1 in complement evasion of Candida albicans [7]. Furthermore, it was found that the expression is glucose-dependent [14]. To visualize the importance of this protein in virulence, the HGT1 knockout mutant hgt1-/and the parental strain SN152 were studied in a murine model of disseminated candidiasis.

When euglycemic mice were intravenously injected with $6 \times 10^{2}$ yeast cells of the parental strain per gram mouse, this Candida albicans strain showed minimal virulence (Figure 1A). Diabetic animals infected with the same amount of yeast cells presented a significantly aggravating course of infection resulting in having to sacrifice $66.7 \%$ of the animals used for the experiment within 14 days (Figure 1A). SN152 induced the highest 
lethality in C3 deficient mice, in which the intravenous challenge led to a lethal outcome in all infected animals within two days (Figure 1A).

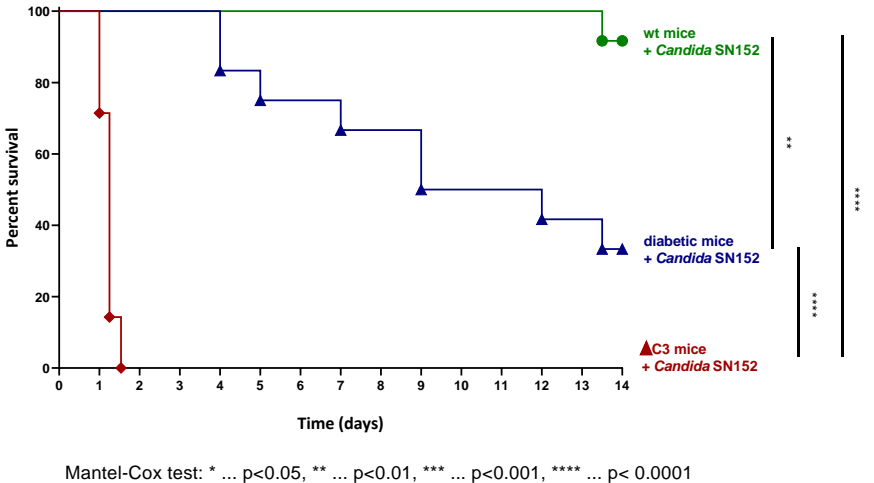

(A)

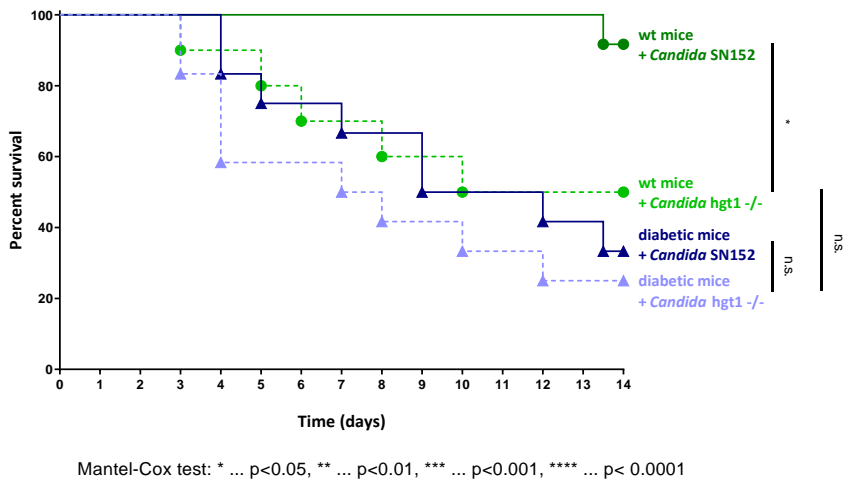

(B)

Figure 1. Survival curves in a murine model of candidemia. Euglycemic (wt, $n=12)$, diabetic $(n=12)$, and $C 3$ deficient $(\Delta C 3, n=7)$ animals were intravenously injected with $6 \times 10^{2}$ Candida albicans cells of the parental strain SN152 per gram mouse (A). Survival curves of $\mathrm{wt}\left(\mathrm{n}_{\text {Candida } \mathrm{SN152}}=12, \mathrm{n}_{\text {Candida }}\right.$ hgt1-/- $=8)$ and diabetic animals $(n=12)$ challenged with $6 \times 10^{2}$ yeast cells of either Candida albicans SN152 (-) or the HGT1 knockout mutant (hgt1-/-, - ) per gram mouse were compared (B). The survival was monitored for 14 days. Stars $\left(^{*}\right)$ indicate the level of significance for a $p$-value resulting from a Mantel-Cox test analyzing pairs of survival curves.

Although it was revealed by us that Hgt1 is a complement evasion molecule [7], knocking out HGT1 surprisingly led to a significantly higher virulence of Candida albicans compared to SN152 in euglycemic mice (Figure $1 B ; \chi^{2}(1)=5.306, p=0.0213$ ). In diabetic animals, the same tendency was observed, but without a significant difference in virulence (Figure 1B). In contrast to SN152, challenging diabetic animals with $6 \times 10^{2}$ yeast cells per gram mouse of the hgt1-/- did not lead to a significantly higher lethality compared to euglycemic mice infected with the same amount of yeast cells (Figure 1B).

\subsection{Effect of Glucose on PMN-Mediated Phagocytosis}

To reveal the reason for the higher virulence of the HGT1 knockout strain of Candida albicans compared to the parental strain SN152 in the murine model, further in vitro analyses were performed. It was shown previously that depletion of neutrophils causes worse outcomes of candidiasis in disseminated, oropharyngeal, and vaginal candidiasis $[15,16]$. It is essential to know whether Candida grown at different glucose concentrations alters the phagocytosis ability of polymorphonuclear leukocytes (PMNs) in addition to the dysfunction of neutrophils in hyperglycemia [17]. After growing the different strains in $0.1 \%, 0.2 \%, 0.3 \%$, or $2 \%$ glucose, and co-incubating the serum-opsonized and FITC-labeled yeast cells with PMNs, the samples were analyzed using flow cytometry.

The results revealed that the glucose concentration in which the Candida albicans wild type strain SC5314 was incubated had a minor effect on both the percentage of PMNs phagocytosing yeast cells (Figure 2A left panel) and the amount of SC5314 cells phagocytosed by PMNs (Figure 2B left panel). Nevertheless, a tendency towards a lower percentage of PMNs phagocytosing yeast cells with higher glucose concentration could be seen (Figure 2A left panel). Additionally, it was shown that there was a tendency of fewer yeast cells being phagocytosed by PMNs with higher glucose concentration (Figure $2 \mathrm{~B}$ left panel). 


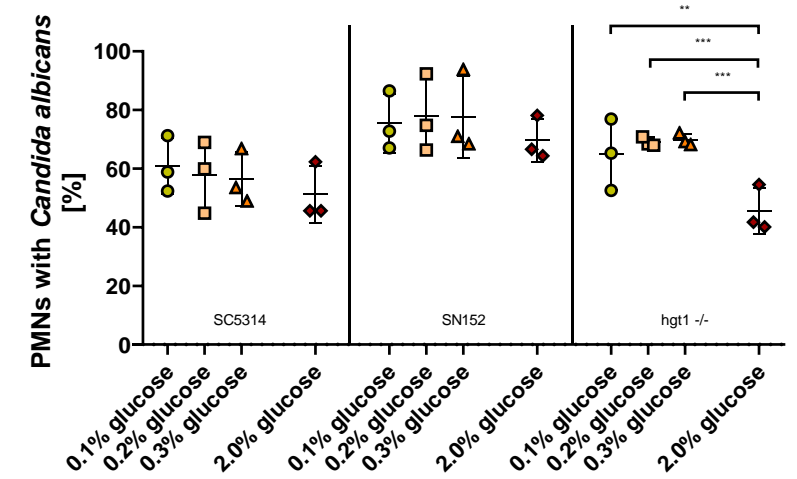

Tukey post-hoc test: ${ }^{*} \ldots \mathrm{p}<0.05,{ }^{\star \star} \ldots \mathrm{p}<0.01,{ }^{\star \star \star} \ldots \mathrm{p}<0.001,{ }^{\star \star \star *} \ldots \mathrm{p}<0.0001$ (A)

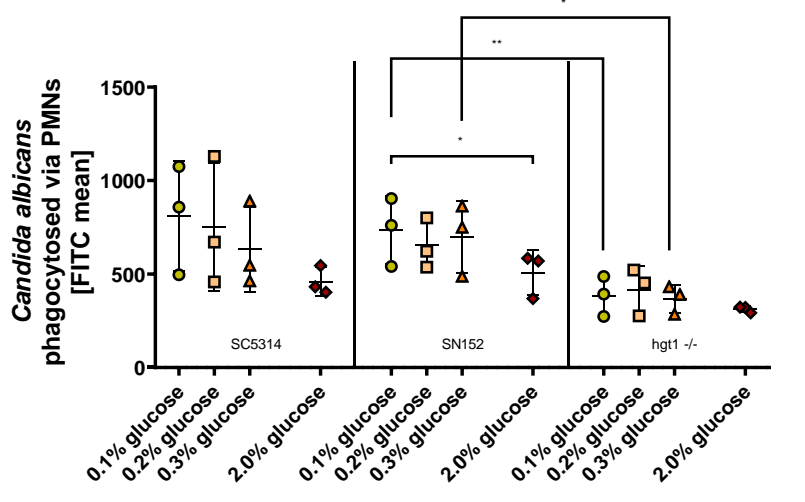

Tukey post-hoc test: ${ }^{*} \ldots \mathrm{p}<0.05,{ }^{\star \star} \ldots \mathrm{p}<0.01,{ }^{\star \star *} \ldots \mathrm{p}<0.001,{ }^{\star \star * *} \ldots \mathrm{p}<0.0001$

(B)

Figure 2. Phagocytosis of opsonized Candida albicans yeast cells grown at different glucose concentrations overnight by polymorphonuclear leukocytes (PMNs). Yeast cells of wild type (SC5314), parental (SN152), and HGT1 knockout (hgt1-/-) strains were incubated in yeast peptone medium with either $0.1 \%, 0.2 \%, 0.3 \%$, or $2 \%$ glucose, opsonized with $40 \%$ normal human serum (NHS) and labeled with fluorescein isothiocyanate (FITC). Freshly isolated PMNs were added and their membrane was labeled with AlexaFluor ${ }^{\circledR}$ 647-conjugated wheat germ agglutinin (WGA). The percentage of double-positive PMNs (A) was measured using fluorescence-activated cell sampler (FACS) Verse with BD software and the amount of phagocytosed Candida albicans yeast cells is shown as FITC mean (B). The results shown were gained by three independently performed experiments (mean \pm SD). Stars $(*)$ indicate the level of significance for an adjusted $p$-value, comparing pairs of groups using a Tukey post-hoc analysis after the one-way ANOVA reported significance.

The parental strain SN152, although apparently being phagocytosed by more PMNs compared to the wild type strain, showed no significant difference between the physiological glucose concentrations (Figure 2A middle panel). A tendency towards lower phagocytosis was observed when comparing these low glucose concentrations with $2 \%$ glucose (Figure 2A middle panel). Moreover, fewer SN152 yeast cells, which have previously been incubated in $2 \%$ glucose, were phagocytosed by each PMN compared to the yeast cells of the same strain incubated in $0.1 \%$ glucose (Figure $2 \mathrm{~B}$ middle panel). The conducted one-way ANOVA revealed that this difference was significant, $\mathrm{F}(3,8)=4.275, p=0.0446$.

Regarding the amount of PMNs phagocytosing hgt1-/- yeast cells, the percentage differed between $2 \%$ glucose and each physiological glucose concentration, while it did not differ within the physiological glucose concentrations (Figure $2 \mathrm{~A}$ right panel). These differences were shown significant by a one-way ANOVA, $\mathrm{F}(3,8)=24.76, p=0.0002$. The Tukey post-hoc analysis revealed that the mean percentage of PMNs phagocytosing Candida cells was significantly decreased in yeast cells grown in $2 \%$ glucose compared to $0.1 \%$ glucose $(-19.44,95 \%$ CI $(-29.87,-9.019), p=0.0015), 0.2 \%$ glucose $(-23.62,95 \%$ CI $(-34.05,-13.2), p=0.0004)$, and $0.3 \%$ glucose $(-24.4,95 \%$ CI $(-34.82,-13.98), p=0.0003$; Figure 2A right panel). Like SN152, the HGT1 knockout mutant (hgt1-/-) did not show any significant difference for the amount of yeast cells phagocytosed by PMNs when incubated at physiological glucose concentrations (Figure 2B right panel). In contrast to SN152, no significant difference could be shown in FITC mean between physiological glucose concentrations and the yeast cells incubated in $2 \%$ glucose (Figure $2 \mathrm{~B}$ right panel). However, comparing the FITC mean of hgt1-/- to SN152, fewer hgt1-/- cells were phagocytosed at all glucose concentrations (Figure 2B middle and right panel). A conducted one way ANOVA and following Tukey post-hoc test revealed that this visible difference was significant at $0.1 \%$ glucose $(-350.7,95 \%$ CI $(-638.5,-62.84), p=0.0084)$ and $0.3 \%$ glucose $(-331.4,95 \%$ CI $(-619.3,-43.61), p=0.0147)$. 


\subsection{Effect of Glucose on the Deposition of $\mathrm{C} 3 \mathrm{~b} / \mathrm{iC} 3 \mathrm{~b}$ on C. albicans}

C3 deficient mice of the conducted murine model exhibited the worst outcome when challenged with Candida albicans cells. Since iC3b acts as an opsonizing molecule and stimulates internalization by interaction with receptors on phagocytes [1], the C3b and iC $3 \mathrm{~b}$ deposition on Candida albicans grown at different glucose concentrations needed checking. For this the different Candida strains were grown in $0.1 \%, 0.2 \%, 0.3 \%$, or $2 \%$ glucose, opsonized with human serum, adding an anti-C3b/iC3b antibody, and analyzed using flow cytometry.

Analyzing the samples showed that the most $\mathrm{C} 3 \mathrm{~b} / \mathrm{iC} 3 \mathrm{~b}$ was deposited on the surface of wild type strain SC5314, which was incubated with $0.1 \%$ glucose $(\mathrm{M}=3973, \mathrm{SD}=890.9)$ compared with the other tested glucose concentrations and strains (Figure 3 left panel). The Tukey post-hoc analysis revealed, that within the wild type strain the cells incubated in media with $0.1 \%$ glucose overnight displayed more $\mathrm{C} 3 \mathrm{~b} / \mathrm{iC} 3 \mathrm{~b}$ on their cell surface than those incubated in $0.2 \%$ glucose $(753.3,95 \% \mathrm{CI}(151.7,1355), p=0.0139), 0.3 \%$ glucose $(812.8$, $95 \%$ CI $(211.2,1414), p=0.0085)$, and $2 \%$ glucose $(964.5,95 \%$ CI $(362.8,1566), p=0.0026)$. Apart from these significant differences, a tendency of lower $\mathrm{C} 3 \mathrm{~b} / \mathrm{iC} 3 \mathrm{~b}$ deposition with increasing glucose concentration on this strain was observed (Figure 3 left panel).

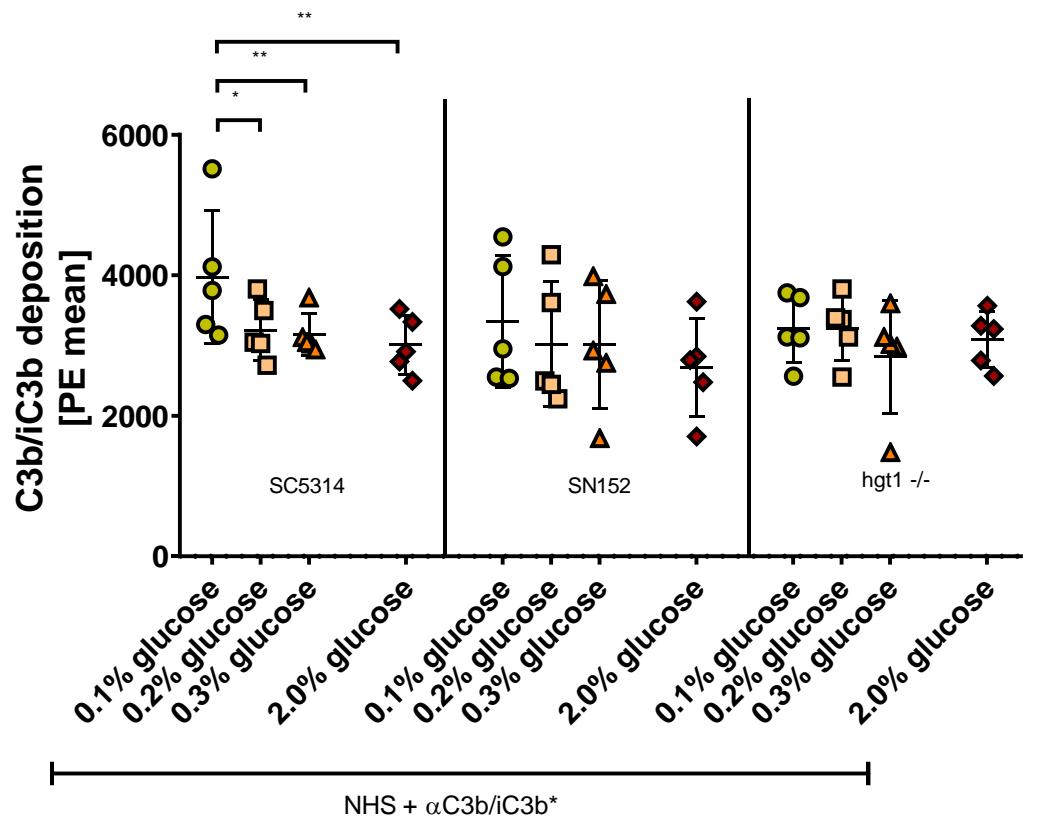

Tukey post-hoc test: ${ }^{*} \ldots \mathrm{p}<0.05,{ }^{* *} \ldots \mathrm{p}<0.01,{ }^{* * *} \ldots \mathrm{p}<0.001,{ }^{* * * *} \ldots \mathrm{p}<0.0001$

Figure 3. $\mathrm{C} 3 \mathrm{~b} / \mathrm{iC} 3 \mathrm{~b}$ deposition on the surface of Candida albicans yeast cells incubated overnight at different glucose concentrations. Yeast cells of wild type (SC5314), parental (SN152), and HGT1 knockout (hgt1-/-) strains were incubated in yeast peptone medium with either $0.1 \%, 0.2 \%, 0.3 \%$, or $2 \%$ glucose and opsonized with $10 \%$ normal human serum (NHS). A specific anti C $3 \mathrm{~b} / \mathrm{iC} 3 \mathrm{~b}$ antibody $(\alpha \mathrm{C} 3 \mathrm{~b} / \mathrm{iC} 3 \mathrm{~b})$ was used and the deposition was measured using fluorescence-activated cell sampler (FACS) Verse with BD software. The deposition of $\mathrm{C} 3 \mathrm{~b} / \mathrm{iC} 3 \mathrm{~b}$ is shown in phycoerythrin (PE) mean. The results shown were gained by five independently performed experiments (mean \pm SD). Stars $\left(^{*}\right)$ indicate the level of significance for an adjusted $p$-value, comparing pairs of groups using a Tukey post-hoc analysis after the one-way ANOVA reported significance.

A conducted one-way ANOVA showed no significant difference between SN152 yeast cells grown at the different glucose concentrations. Nevertheless, a tendency for lower $\mathrm{C} 3 \mathrm{~b} / \mathrm{iC} 3 \mathrm{~b}$ deposition on the cell surface with increasing glucose concentration was visible (Figure 3 middle panel). 
In contrast to SC5314 and SN152 yeast cells, for the HGT1 knockout strain (hgt1-/-), no difference or tendency in $\mathrm{C} 3 \mathrm{~b} / \mathrm{iC} 3 \mathrm{~b}$ deposition on the cell surface was detected (Figure 3 right panel).

\subsection{Effect of Glucose on the Deposition of FH on C. albicans}

Factor $\mathrm{H}(\mathrm{FH})$ is used by Candida albicans to avoid detrimental effects from complement [18]. To enlighten the effect of glucose on the deposition of this protein on the surface of Candida cells, an in vitro experiment was conducted with yeast cells incubated overnight in either $0.1 \%, 0.2 \%, 0.3 \%$, or $2 \%$ glucose and opsonized with human serum. To detect the amount of FH on the surface of these cells, an anti-FH antibody was added and flow cytometry was used to measure the samples.

Regarding the wild type strain SC5314, a tendency for higher FH deposition with higher glucose concentration was observed (Figure 4 left panel). Tukey post-hoc analysis revealed that on SC5314 yeast cells incubated in 2\% glucose, significantly more $\mathrm{FH}$ is binding than on yeast cells of the same strain incubated in $0.1 \%$ glucose $(80.89,95 \% \mathrm{CI}$ $(9.219,152.6), p=0.0282)$ (Figure 4 left panel), which correlates negatively with the C $3 \mathrm{~b} / \mathrm{iC} 3 \mathrm{~b}$ deposition on this strain (Figure 3 left panel).

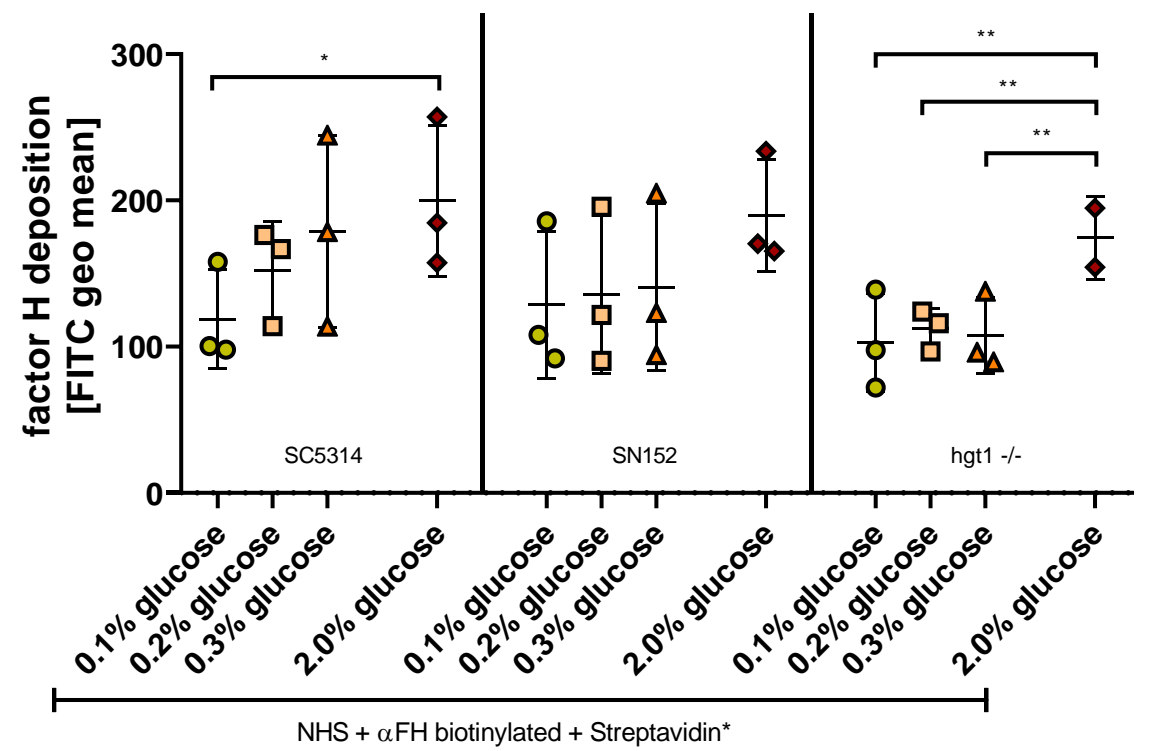

Tukey post-hoc test: ${ }^{*} \ldots \mathrm{p}<0.05,{ }^{* *} \ldots \mathrm{p}<0.01,{ }^{* * *} \ldots \mathrm{p}<0.001,{ }^{* \star * *} \ldots \mathrm{p}<0.0001$

Figure 4. Factor $\mathrm{H}(\mathrm{FH})$ deposition on the surface of Candida albicans yeast cells incubated overnight at different glucose concentrations. Yeast cells of wild type (SC5314), parental (SN152), and HGT1 knockout (hgt1-/-) strains were incubated in yeast peptone medium with either $0.1 \%, 0.2 \%, 0.3 \%$, or $2 \%$ glucose and opsonized with $40 \%$ normal human serum (NHS). A specific anti-FH antibody $(\alpha \mathrm{FH})$ was used and the deposition was measured using fluorescence-activated cell sampler (FACS) Verse with BD software. The deposition of FH is shown in fluorescein isothiocyanate (FITC) geometric mean (geo mean). The results shown were gained by three independently performed experiments (mean $\pm \mathrm{SD}$ ). Stars $\left(^{*}\right)$ indicate the level of significance for an adjusted $p$-value, comparing pairs of groups using a Tukey post-hoc analysis after the one-way ANOVA reported significance.

This negative correlation with the $\mathrm{C} 3 \mathrm{~b} / \mathrm{iC} 3 \mathrm{~b}$ deposition was also detected as a visible, albeit not significant, tendency in the parental strain SN152 (Figure 4 middle panel; Figure 3 middle panel).

Unlike the yeast cells of SC5314 and SN152, the HGT1 knockout mutant hgt1-/- did not show any differences in FH deposition when comparing the physiological glucose concentrations (Figure 4 right panel), which correlates with the $\mathrm{C} 3 \mathrm{~b} / \mathrm{iC} 3 \mathrm{~b}$ results described above (Figure 3 right panel). In contrast to the $\mathrm{C} 3 \mathrm{~b} / \mathrm{iC} 3 \mathrm{~b}$ deposition (Figure 3 right panel), 
the FH deposition on hgt1-/- yeast cells grown in $2 \%$ glucose did however differ from the physiological glucose concentrations (Figure 4 right panel). A conducted Tukey post-hoc analysis showed that significantly less $\mathrm{FH}$ is binding to the cell surface of hgt1-/- grown in $0.1 \%(-71.61,95 \%$ CI $(-112.4,-30.77), p=0.0022), 0.2 \%(-62.28,95 \%$ CI $(-103.1,-21.44)$, $p=0.0053)$, and $0.3 \%$ glucose $(-66.83,95 \% \mathrm{CI}(-107.7,-26.00), p=0.0035)$.

\section{Discussion}

Understanding the mechanisms behind the pathogenesis of candidiasis is crucial to finding new approaches to treat patients suffering from this disease, accounting for an estimated 10,000 deaths per year in Europe [19]. Hence, we here analyzed the relevance of the complement system, as an essential part of the innate immunity, and glucose on the pathogenesis of Candida albicans. We investigated three aspects of the interplay of Candida albicans, the complement system, and glucose. Firstly, we studied in vitro the effect of glucose on the phagocytosis of three different Candida albicans strains grown in $0.1 \%$, $0.2 \%, 0.3 \%$, or $2 \%$ glucose and opsonized with human serum by granulocytes. We used the following strains: a wild type strain (SC5314), a high-affinity glucose transporter 1 knockout strain (hgt1-/-), which is lacking Hgt1, a factor H-binding molecule known for a glucose-dependent expression, and its parental strain (SN152). Patients suffering from diabetes mellitus experience several modulations of cellular and humoral defenses including the complement system [20]. With respect to cellular defenses, hyperglycemia particularly affects the functions of neutrophils, essential for eliminating pathogens. High glucose concentrations impede phagocytosis of lipopolysaccharide-coated particles [21], opsonized Gram-negative and Gram-positive bacteria [22], and Staphylococcus aureus [23]. In this study, we showed that the phagocytosis of Candida albicans SC5341 and SN152 is also decreased at higher glucose concentrations. For the HGT1 knockout mutant (hgt1-/-), there was no difference in phagocytosis detected within physiological glucose concentrations $(0.1-0.3 \%)$. Nevertheless, in unphysiological high $2 \%$ glucose, the percentage of granulocytes phagocytosing hgt1-/- decreased compared to physiological glucose concentrations, while the amount of phagocytosed cells did not differ. However, the differences in phagocytosis were weak and much less pronounced than expected.

Secondly, we checked whether glucose has an effect on the yeast cell surface of Candida albicans altering in particular the $\mathrm{C} 3 \mathrm{~b} / \mathrm{iC} 3 \mathrm{~b}$ deposition and $\mathrm{FH}$ deposition. Besides the immune system being altered by hyperglycemia, it was also shown that high glucose concentrations lead to modifications on the pathogen side such as increased adhesion, invasion [24], and stress resistance [25] of Candida albicans. The in vitro experiments performed in this study showed an additional alteration of Candida albicans strains by glucose. The incubation of Candida albicans SC5314 and SN152 at different glucose concentrations led to a lower $\mathrm{C} 3 \mathrm{~b} / \mathrm{iC} 3 \mathrm{~b}$ deposition with increasing glucose concentration. It is known that glucose binds to the biochemically active site of $\mathrm{C} 3$ at high glucose concentrations in a nonenzymatic manner, changing the tertiary structure of the molecule, inhibiting the activation of C3b by Staphylococcus aureus, and the deposition of C3b and iC3b on Staphylococcus aureus [26,27]. Since we wanted to investigate the role of glucose on Candida albicans alone, we circumvented this effect of glucose on the complement by executing several washing steps and therefore removing residual glucose before the opsonization with normal human serum. Besides the altered $\mathrm{C} 3 \mathrm{~b} / \mathrm{iC} 3 \mathrm{~b}$ deposition, we also showed higher $\mathrm{FH}$ deposition with increasing glucose concentrations.

However, as indicated before, it must be stated that the effects of the glucose concentration in vitro were much less pronounced than expected.

Further investigations are needed to clarify the mechanisms behind the glucosedependent alterations of Candida albicans that might interfere with the complement deposition.

When growing in a host, pathogens and commensals alike have to face the innate immunity. To avoid recognition or destruction by the immune system, microorganisms have evolved several immune evasion mechanisms. Especially the complement system 
as a crucial bridge between the innate and the adaptive immunity is often the target for these evasion mechanisms. One of these is to bind factor $\mathrm{H}(\mathrm{FH})$, which is the major soluble regulator of the alternative pathway, to their surface [28]. We here showed, as mentioned above, that FH binding in Candida albicans is glucose-dependent. We revealed that knocking out HGT1 diminishes this glucose dependency of FH, except at $2 \%$ glucose. Besides Hgt1, the expression of another FH-binding molecule of Candida albicans is linked to glucose, namely Gpd2. While the gene expression of GPD2 is up-regulated at higher glucose concentrations [25], the gene expression of HGT1 was found to be significantly lower in high glucose compared to euglycemic glucose levels [14]. This up-regulation of Gpd2 might be responsible for the increased FH deposition on hgt1-/- incubated at $2 \%$ glucose.

Thirdly, we examined whether the absence of Hgt1 or C3 can be linked to the survival in a murine model. We therefore intravenously challenged euglycemic, diabetic, and C3-deficient mice with SN152 and in addition euglycemic and diabetic mice with hgt1-/-. Survival and clinical status were monitored over 14 days. Although it was shown previously that Candida albicans can escape mouse neutrophils unlike human neutrophils by outgrowing as hyphae [29], the lethality in euglycemic mice was low in our study. As demonstrated in several other studies [30-32], the outcome of a systemic Candida albicans infection was worse in diabetic animals, which can be explained by altered cellular and humoral defenses in hyperglycemia as elaborated above [20]. Furthermore, Candida albicans exhibits an increased resistance towards oxidative and cationic stress at higher glucose concentrations [25]. These stress responses might lead to better protection against the antimicrobial properties of phagocytes, which rely either on oxidative burst [33] or the influx of cations [34]. Additionally, we could show the crucial part of C3 in defense against Candida albicans SN152 in immunosuppressed animals. This is supported by the findings of Tsoni and coworkers regarding the wild type strain SC5314, which exhibited a higher virulence in C3 deficient animals [35]. When conducting our study, knocking out C3 was thought to result in lacking complement opsonization, but the formation of the membrane attack complex (MAC) could still work due to thrombin cleaving C5 into C5a and C5b [36]. It was revealed recently that a conformational change of $\mathrm{C} 5$ is needed for this thrombinmediated cleavage and is therefore probably not happening in vivo or solely under certain circumstances [37]. We hypothesize that other components could be able to cleave C5 due to a similar inflammation reaction shown by Tsoni [35].

When knocking out HGT1, a complement evasion molecule, the resulting hgt1-/strain should have shown a reduced virulence in a murine model due to reduced $\mathrm{FH}$ deposition and the subsequent exerted functions by this major regulator protein of the alternative pathway [9]. In contrast to this hypothesis, the murine model revealed that knocking out HGT1 in Candida albicans increased the virulence of the resulting hgt1-/strain in euglycemic mice. In addition, in diabetic mice SN152 showed a comparably high virulence, which might be due to the downregulation of Hgt1 in this strain at higher glucose concentrations shown in our previous work [14]. Furthermore, the reduced FH deposition on Candida albicans hgt1-/- incubated at physiological glucose concentrations did not lead to a markedly higher phagocytosis. On the contrary, fewer hgt1-/- incubated at physiological glucose concentrations were phagocytosed compared to SN152. This could be explained by a different property of $\mathrm{FH}$ : besides regulating the complement system by inactivating $\mathrm{C} 3 \mathrm{~b}$ and accelerating the decay of the $\mathrm{C} 3$ - and $\mathrm{C} 5$-convertase of the alternative pathway [9], it binds complement receptor 3 (CR3, CD11b/CD18) [38]. CR3, a receptor, is inter alia involved in phagocytosis and mainly expressed on macrophages, monocytes, granulocytes, and natural killer cells. Candida-bound FH interacts with CR3, therefore bridging the pathogen to professional phagocytes like PMNs and supporting the clearance of Candida albicans [38,39] (Figure 5). 

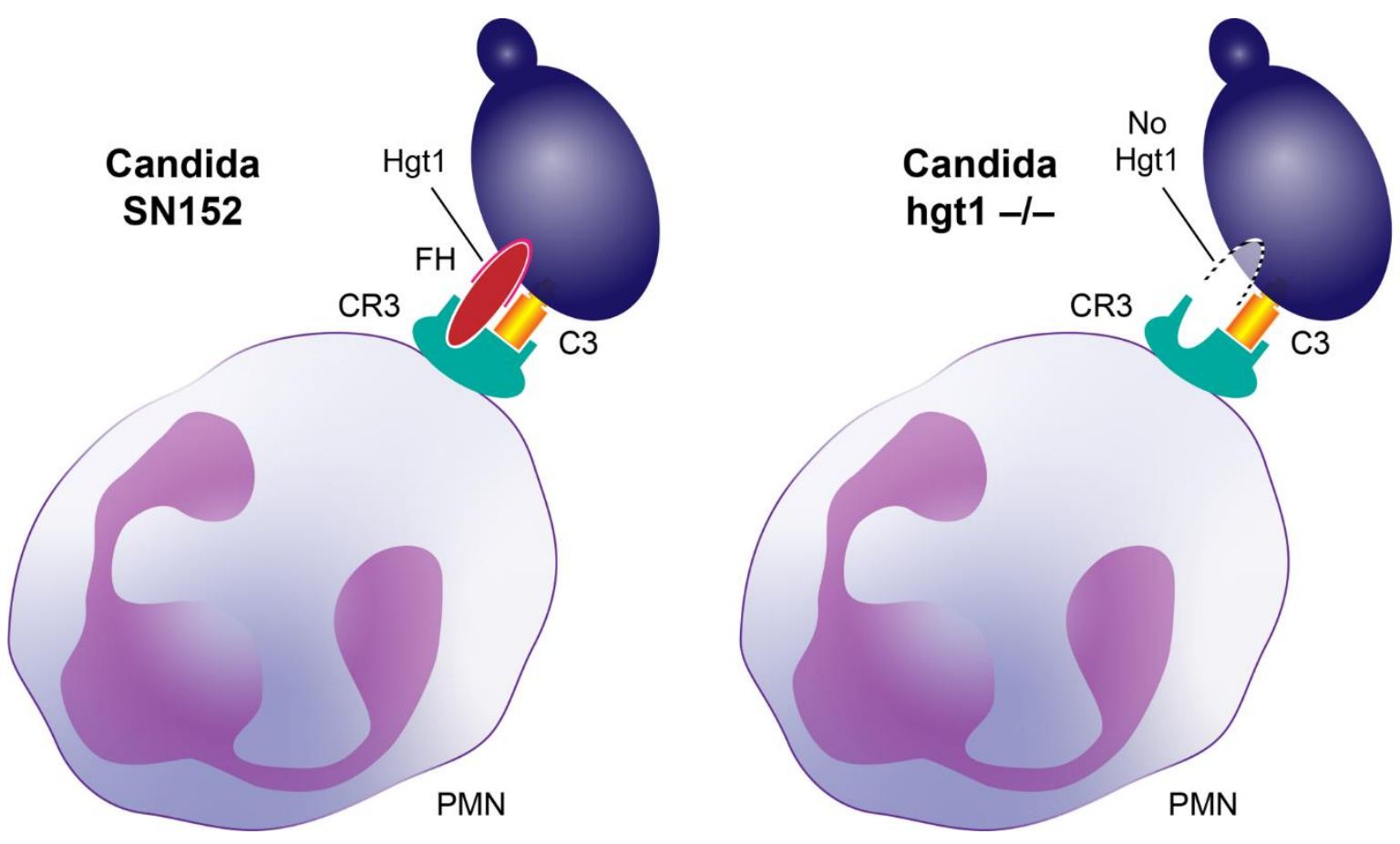

Figure 5. Factor $\mathrm{H}(\mathrm{FH})$ bridging Candida albicans cells to professional phagocytes. Both activated $\mathrm{C} 3$ (hatched yellow box) and FH (red ellipse) bind to complement receptor 3 (CR3, cyan receptor). Upon opsonization, activated C3 is deposited on Candida albicans (violet cell) and FH binds to its receptor on the yeast (such as Hgt1). Left: binding of Candida albicans parental strain (SN152) to the phagocyte CR3 via both FH and activated C3. Right: Proposed model of an assumed less efficient binding of Candida albicans hgt1-/- mutant lacking an important FH-binding molecule (indicated by dotted line) via just activated $\mathrm{C} 3$ to the phagocyte $\mathrm{CR} 3$ (in vivo some $\mathrm{FH}$ molecules will obviously bind, but with lower affinity).

Confirming the relevance of CR3 in Candida infections, mice deficient in CR3 presented with an aggravating course of infection compared to age-matched control mice [40]. The strongest support for our murine model is the findings of Soloviev and coworkers, who monitored the virulence of Candida albicans Pra1 deletion mutant compared to a CAI-12 as a control strain and gained similar results to those of our murine model, namely that the elimination of the FH-binding molecule leads to a higher virulence of the mutant strain [40]. FH bridging the pathogen to phagocytes can explain the hgt1-/- mutant results mentioned above.

To elucidate whether the induction of FH-binding molecules such as Pra1 or Hgt1 may represent a new therapeutic approach to tackle Candida infections, a mutant overexpressing Pra1 or Hgt1 has to be generated. Such mutant(s) can be used to compare the phagocytosis in vitro with the parental strain and, if proven promising, translated into a murine model.

Regarding the media, which are normally used to grow Candida albicans, these mostly contain $2 \%$ glucose like YPD, yeast nitrogen base (YNB), and synthetic low ammonium dextrose (SLAD) [41]. Alternative media for Candida albicans, which should be used if the results should depict physiological conditions, would be Medium 199, serum agar medium, spider medium, and Lee's medium containing either $0.1 \%$ or $0.24 \%$ glucose [41]. These glucose concentrations are those of euglycemic or prediabetic patients [11]. The same issue can be observed with antifungal susceptibility testing (AFST) methods, which are performed using high glucose concentrations to ensure fungal growth. When working according to the EUCAST guidelines, RPMI with $2 \%$ glucose is needed for the broth microdilution method [42,43]; according to the CLSI guidelines, either $0.2 \%$ glucose is used for the broth microdilution method or $2 \%$ glucose for the agar diffusion method [43,44], and the agar plates for the agar diffusion Etest method contain $2 \%$ glucose [43]. The difference 
in glucose concentrations used in these methods could be partially responsible for the differences in the minimum inhibitory concentrations (MICs) when testing the same strains using different methods [43], and thus physiological glucose concentration should always be considered.

\section{Materials and Methods}

\subsection{Reagents and Media}

Streptozotocin, Histopaque-1077, RPMI 1640 with L-glutamine, without glucose and sodium bicarbonate, sodium phosphate dibasic $\left(\mathrm{Na}_{2} \mathrm{HPO}_{4}\right)$, fetal calf serum (FCS), bovine serum albumin (BSA), ethylene glycol-bis ( $\beta$-aminoethyl ether) tetraacetic acid (EGTA), t-Octylphenoxypolyethoxyethanol (Triton X-100), trypan blue solution $0.4 \%$, and fluorescein isothiocyanate (FITC) isomer I were purchased from Sigma Aldrich (St. Louis, MO, USA). Sodium hydrogen bicarbonate $\left(\mathrm{NaHCO}_{3}\right)$, sodium dihydrogen phosphate dihydrate $\left(\mathrm{NaH}_{2} \mathrm{PO}_{4} \times 2 \mathrm{H}_{2} \mathrm{O}\right)$, yeast extract, and Tween 20 were obtained from MERCK (Darmstadt, Germany). D (+)-glucose, peptone from soy, agar, sodium chloride $(\mathrm{NaCl})$, calcium chloride $\left(\mathrm{CaCl}_{2}\right)$, magnesium chloride hexahydrate $\left(\mathrm{MgCl}_{2} \times 6 \mathrm{H}_{2} \mathrm{O}\right)$, ethylenediaminetetraacetic acid (EDTA), formaldehyde solution 37\%, and sodium carbonate anhydrous $\left(\mathrm{Na}_{2} \mathrm{CO}_{3}\right)$ were bought from Carl Roth (Karlsruhe, Germany). Fluorescein isothiocyanate (FITC)-conjugated streptavidin was ordered from Invitrogen AG (Carlsbad, CA, USA). Phycoerythrin (PE)-conjugated anti-human $\mathrm{C} 3 \mathrm{~b} / \mathrm{iC} 3 \mathrm{~b}$ antibody and biotinylated mouse anti-human factor $\mathrm{H}(\mathrm{FH})$ were supplied by BioLegend (San Diego, CA, USA). Alexa Fluor ${ }^{\circledR}$ 647-conjugated wheat germ agglutinin (WGA) was purchased from Life Technologies (Carlsbad, CA, USA).

\subsection{Mice}

C57Bl/6J mice were purchased from Charles River Laboratories (Sulzfeld, Germany) and used as controls (wild type mice; wt) or $130 \mu \mathrm{g} / \mathrm{g}$ streptozotocin, which is toxic for the insulin-producing beta cells of the pancreas, was administered intraperitoneally to obtain diabetic mice. $\mathrm{C} 3$ deficient $(\Delta \mathrm{C} 3)$ mice are genetically modified $\mathrm{C} 57 \mathrm{Bl} / 6$ mice and bred at the Institute of Hygiene and Medical Microbiology in Innsbruck. The murine experiments were conducted in conformity with national law and guidelines of the European Communities and performed at the Institute of Hygiene and Medical Microbiology in Innsbruck. The mice were housed at a 12-h alternating light-dark cycle and provided with standardized feed and sterilized water ad libitum. Five percent saccharose was added to the sterilized water of diabetic mice.

\subsection{Candida albicans Strains}

The Candida albicans strains used were SC5314 (a wild type genotype) as control strain and SN152 (a strain auxotrophic for arginine, leucine, and histidine) as parental strain. The latter was used for knocking out HGT1 (hgt1-/-) according to standard protocols [45]. The mutant strain was generated previously by Lesiak-Markowicz and colleagues [7]. The strains were routinely maintained on YPD agar (yeast extract $1 \%$, peptone from soy $2 \%$, D (+)-glucose $2 \%$, and agar $1.5 \%$ ) plates. For the $\mathrm{FH}$ and $\mathrm{C} 3 \mathrm{~b} / \mathrm{iC} 3 \mathrm{~b}$ deposition on Candida albicans surface and the PMN mediated fungal killing, an overnight $(\mathrm{O} / \mathrm{N})$ culture of each strain was grown at $30{ }^{\circ} \mathrm{C}$ and under gentle shaking in YP-medium containing $0.1 \%, 0.2 \%, 0.3 \%$, or $2 \%$ glucose. For the murine model of disseminated candidiasis, an $\mathrm{O} / \mathrm{N}$ culture of SN152 and hgt1-/- was produced in YP-medium containing $0.1 \%, 0.4 \%$, or $2 \%$ glucose, incubated at $30^{\circ} \mathrm{C}$ and under gentle shaking.

\subsection{Murine Model of Disseminated Systemic Candidiasis}

For the model of disseminated Candida infection, groups of seven to twelve 7-week-old mice were infected intravenously with yeast cells of either Candida albicans SN152 or hgt1-/strain $\left(6 \times 10^{2} / \mathrm{g}\right.$ mouse in $\left.100 \mu \mathrm{L} 0.9 \% \mathrm{NaCl}\right)$. Candida strains used for the infection of euglycemic (wt) mice were grown in YP-medium containing $0.1 \%$ glucose overnight 
before inoculation. For $\triangle \mathrm{C} 3$ mice, an overnight culture of the different Candida strains grown in YP-medium containing 2\% glucose was used, and for diabetic animals, the strains were grown in YP-medium containing $0.4 \%$ glucose before inoculation. All mice were immunosuppressed starting at day -4 before infection with $50 \mu \mathrm{g} / \mathrm{g}$ cyclophosphamide. This medication was attributed every second day to maintain the immunosuppression. To induce diabetes $130 \mu \mathrm{g} / \mathrm{g}$ streptozotocin was administered intraperitoneally at day -10 prior to infection. Furthermore, $5 \%$ saccharose was added to the distilled drinking water from day -9 forward and blood sugar was controlled before the infection at day -6 and day -3 . If the blood sugar level was too low, additional streptozotocin was administered, depending on the measured blood sugar. One hundred micrograms per gram of streptozotocin was administered at blood glucose levels of $<10 \mathrm{mmol} / \mathrm{L}, 70 \mu \mathrm{g} / \mathrm{g}$ at $10-12.5 \mathrm{mmol} / \mathrm{L}$, and $40 \mu \mathrm{g} / \mathrm{g}$ at $12.5-15 \mathrm{mmol} / \mathrm{L}$. After infection, the sugar levels in blood and urine were measured regularly. Body weight and temperature were determined twice a day. A clinical assessment was performed at least twice a day after the infection. Blood and urine samples were obtained on day 1 , day 8 , and the day of exitus, which was either day 14 post-infection or when the animals met humane endpoints [46] as defined in the animal proposal, such as loss of body weight, loss of mean body temperature, missing intake of water or food, and appearance of neurological symptoms. On the day of exitus, animals were euthanized by cervical dislocation under isoflurane anesthesia [47]. The Federal Ministry of Education, Science and Research, Republic of Austria approved the conducted animal experiments (BMWFW-66.011/0196-WF/V/3b/2016, BMBWF-66.011/0102-V/3b/2018).

\subsection{Isolation of Polymorphonuclear Leukocytes (PMNs)}

Fresh blood was obtained from informed consent healthy human donors, approved by the Ethics Committee of the Medical University of Innsbruck, Austria (ECS1166/2018, 14 November 2018). A density gradient centrifugation was performed by adding Histopaque1077 and RPMI medium to the EDTA-blood and centrifuging it at $570 \times g$ for $25 \mathrm{~min}$ without break. The supernatant was discarded until $5 \mathrm{~mm}$ above the separation line. The PMNs were situated at the bottom mixed with erythrocytes. To remove surplus Histopaque-1077, the liquid was washed with $1 \times$ PBS and centrifuged with break at $500 \times g$ for $10 \mathrm{~min}$. The supernatant was discarded and hypotonic erythrocyte lysis was performed by adding distilled water to the cell pellet for $20 \mathrm{~s}$. The physiological osmolarity was restored by the addition of the same amount of $2 \times$ PBS. The suspension was centrifuged at $500 \times g$ for $5 \mathrm{~min}$ and the supernatant was removed. Lysis and centrifugation were repeated until the pellet appeared white. The supernatant was discarded and the pellet containing PMNs was resuspended in RPMI medium containing $0.1 \%$ glucose. Purity was determined by light microscopy.

\subsection{PMN-Mediated Phagocytosis of Candida albicans Ex Vivo}

The O/N culture of SC5314, SN152, and hgt1-/- was washed two times with $5 \mathrm{~mL} 1 \times$ PBS and centrifuged at $2000 \times g$ for $5 \mathrm{~min}$. The supernatant was discarded and the pellet was resuspended in $1 \mathrm{~mL} 1 \times \mathrm{PBS}$. Candida yeast cells were opsonized for $30 \mathrm{~min}$ at $37^{\circ} \mathrm{C}$ and $5 \% \mathrm{CO}_{2}$ with $40 \%$ fresh normal human serum (NHS) from an NHS pool and $20 \% 1 \times$ PBS++ $\left(0.15 \mathrm{mM} \mathrm{CaCl}_{2}\right.$ and $1 \mathrm{mM} \mathrm{MgCl} 2$ were added to $\left.1 \times \mathrm{PBS}\right)$ was added. As a control, the NHS was replaced with heat-inactivated NHS, which was achieved by heating the NHS for $30 \mathrm{~min}$ at $60^{\circ} \mathrm{C}$ in a water bath. After the incubation period, the yeast cells were washed two times with $1 \mathrm{~mL} 1 \times$ PBS and centrifuged for $5 \mathrm{~min}$ at $2000 \times \mathrm{g}$. The supernatant was discarded and Candida was resuspended in $1 \mathrm{~mL} 1 \times$ PBS. One milliliter of staining solution, consisting of $9.5 \mathrm{~mL} 0.1 \mathrm{M} \mathrm{Na}_{2} \mathrm{CO}_{3}, 0.5 \mathrm{~mL} 1 \times$ PBS/0.1\% Tween 20 and $1 \mathrm{mg}$ FITC, was added and the cells were incubated for $15 \mathrm{~min}$ at $37^{\circ} \mathrm{C}$. To separate Candida from unbound FITC, the suspension was centrifuged at $900 \times g$ for $6 \mathrm{~min}$, the supernatant discarded, and washed two times with $1 \times$ PBS. After the washing steps, the Candida was resuspended in $1 \mathrm{~mL} 1 \times$ PBS. 
Isolated PMNs were diluted using RPMI with different glucose concentrations, namely $0.1 \%, 0.2 \%, 0.3 \%$, and $2 \%$. A concentration of $1 \times 10^{5}$ PMNs were added to $5 \mathrm{~mL}$ roundbottom tubes containing $1 \times 10^{6}$ FITC-labeled Candida and $100 \mu \mathrm{L} \mathrm{RPMI} / 10 \% \mathrm{FCS}_{\mathrm{HI}}$ (heat-inactivated fetal calf serum). For phagocytosis, the $5 \mathrm{~mL}$ round-bottom tubes were incubated $1 \mathrm{~h}$ at $37{ }^{\circ} \mathrm{C}$ and $5 \% \mathrm{CO}_{2}$, under gently shaking. Thirty minutes before the incubation period ended, $0.5 \mu \mathrm{g}$ WGA Alexa Fluor 647 was used to mark the PMNs. Phagocytosis was stopped by adding $200 \mu \mathrm{L} 1 \times$ PBS/1\% formalin per $5 \mathrm{~mL}$ round-bottom tube and incubating them for $30 \mathrm{~min}$ at room temperature. The samples and controls were washed with $300 \mu \mathrm{L} 1 \times$ PBS, centrifuged at $200 \times g$ for $7 \mathrm{~min}$, and resuspended in $100 \mu \mathrm{L}$ $1 \times$ PBS $/ 1 \%$ formalin, fixed for $30 \mathrm{~min}$ at room temperature, and afterwards, the tubes were covered with parafilm.

The PMN-mediated phagocytosis of labeled yeast cells was measured using the fluorescence-activated cell sampler (FACS) Verse and BD software (BD Bioscience, San Diego, CA, USA). WGA-positive PMNs were gated by APC-A vs. FSC-A color density plot and 10,000 gate events were analyzed. The WGA-positive gate was further investigated for FITC-positivity using a color density plot FITC-A vs. FSC-A.

\subsection{FH and C3b/iC3b Deposition on C. albicans Surface by Fluorescence-Activated Cell Sampling (FACS)}

The O/N culture of SC5314, SN152, and hgt1-/- was washed as described above. One million Candida yeast cells were opsonized for $10 \mathrm{~min}$ at $37^{\circ} \mathrm{C}$ and $5 \% \mathrm{CO}_{2}$ with $40 \%$ NHS from an NHS pool for FH deposition and 10\% NHS for C3b/iC3b deposition, respectively. Fifty percent $\left(\mathrm{v} / \mathrm{v}_{\mathrm{NHS}}\right) 1 \times$ PBS++ was added to supply a sufficient amount of ions necessary for the activation of the complement system. As negative controls, the NHS was either replaced with $1 \times$ PBS or with heat-inactivated NHS. Further controls were achieved by replacing $1 \times$ PBS ++ with either $1 \times$ PBS/0.01 M EDTA, which blocks the activation of all complement pathways, or with $1 \times$ PBS/0.01 M EGTA/0.0025 M MgCl 2 , blocking classical pathway activation. The opsonized cells and controls were washed two times with $300 \mu \mathrm{L}$ $1 \times$ PBS, centrifuged at $3000 \times g$ for $5 \mathrm{~min}$ and the supernatant was discarded. Nonspecific binding sites were blocked with $200 \mu \mathrm{L} 1 \times \mathrm{PBS} / 0.1 \%$ BSA for $30 \mathrm{~min}$ at room temperature, under gentle shaking. Eight microliters biotinylated mouse anti-human FH antibody $(0.6 \mathrm{mg} / \mathrm{mL})$ was directly added to each tube to detect $\mathrm{FH}$ deposition or $5 \mu \mathrm{L}$ PE-conjugated mouse anti-human $\mathrm{C} 3 \mathrm{~b} / \mathrm{iC} 3 \mathrm{~b}(0.1 \mathrm{mg} / \mathrm{mL})$ for $\mathrm{C} 3$ deposition. The samples were incubated at room temperature for $60 \mathrm{~min}$. After the incubation period, the samples were washed with $300 \mu \mathrm{L} 1 \times$ PBS and centrifuged at $3000 \times g$ for $5 \mathrm{~min}$. The supernatant was discarded and the tubes for the $\mathrm{C} 3 \mathrm{~b} / \mathrm{iC} 3 \mathrm{~b}$ deposition were resuspended in $300 \mu \mathrm{L} 1 \times \mathrm{PBS} / 1 \%$ formalin, fixed for $30 \mathrm{~min}$ at room temperature, and afterwards the test tubes were covered with parafilm to avoid evaporation. For the FH deposition, the pellet was resuspended with FITC-conjugated streptavidin diluted 1:50 in 200 $\mu \mathrm{L} \mathrm{1 \times} \mathrm{PBS.} \mathrm{These} \mathrm{samples} \mathrm{were} \mathrm{incubated}$ at room temperature for $60 \mathrm{~min}$. The tubes were washed with $300 \mu \mathrm{L} \mathrm{1x}$ PBS, centrifuged at $3000 \times g$ for $5 \mathrm{~min}$, and resuspended in $300 \mu \mathrm{L} 1 \times \mathrm{PBS} / 1 \%$ formalin, fixed for $30 \mathrm{~min}$ at room temperature, and afterwards, the tubes were covered with parafilm.

The deposition of $\mathrm{FH}$ and $\mathrm{C} 3 \mathrm{~b} / \mathrm{iC} 3 \mathrm{~b}$ were measured independently using the FACS Verse and BD software (BD Bioscience, San Diego, CA, USA). The yeast cells were gated by a SSC-A vs. FSC-A density plot. Ten thousand gate events were analyzed. Single yeast cells were furthermore gated by FSC-H vs. FSC-W. The positive population was detected using a one-color density plot SSC-A vs. FITC-A for anti-FH and SSC-A vs. PE-A for anti-C3b/iC3b.

\subsection{Statistical Analyses}

Data obtained were analyzed and plotted using GraphPad Prism 8. In vitro experiments were performed 3 to 6 times on different days. PMNs were isolated from different healthy donors. To show significant differences, one-way ANOVAs were performed and Tukey post-hoc analyses were used for further analyzing differences between the different 
groups. The survival curves were analyzed using the Mantel-Cox test. The reported $p$-values throughout the manuscript refer to adjusted $p$-values. The threshold for statistical significance was $<0.05$.

Author Contributions: Conceptualization, V.H., S.K. and R.W.; Data curation, V.H.; Funding acquisition, R.W.; Investigation, V.H., S.K., V.F., N.P. and C.S.; Methodology, V.H., S.K. and V.F.; Project administration, R.W.; Resources, C.L.-F. and R.W.; Supervision, C.S. and R.W.; Validation, G.R., N.P. and R.W.; Visualization, V.H., C.X.W. and P.G.; Writing-original draft, V.H.; Writing-review \& editing, S.H. and R.W. All authors have read and agreed to the published version of the manuscript.

Funding: This research was funded by Austrian Science Fund (FWF) Doctoral Program of Excellence HOROS, HOROS W-1253 and the Land Tirol, F.17608.

Institutional Review Board Statement: The study was conducted in accordance with the Declaration of Helsinki, and approved by the Ethics Committee of the Medical University of Innsbruck, Austria (ECS1166/2018, 14 November 2018). The animal study protocols were approved by the Federal Ministry of Education, Science and Research, Republic of Austria (BMWFW-66.011/0196-WF/V/3b/2016, 01 December 2016; BMBWF-66.011/0102-V/3b/2018, 10 August 2018).

Informed Consent Statement: Informed consent was obtained from all subjects involved in the study.

Data Availability Statement: Not applicable.

Conflicts of Interest: The authors declare no conflict of interest.

\section{References}

1. Rambach, G.; Wurzner, R.; Speth, C. Complement: An efficient sword of innate immunity. Contrib. Microbiol. 2008, 15, 78-100.

2. Kopp, A.; Hebecker, M.; Svobodova, E.; Jozsi, M. Factor h: A complement regulator in health and disease, and a mediator of cellular interactions. Biomolecules 2012, 2, 46-75. [CrossRef]

3. Suzuki, S. Immunochemical study on mannans of genus candida. I. Structural investigation of antigenic factors $1,4,5,6,8,9,11$, 13, 13b and 34. Curr. Top Med. Mycol. 1997, 8, 57-70.

4. Gropp, K.; Schild, L.; Schindler, S.; Hube, B.; Zipfel, P.F.; Skerka, C. The yeast candida albicans evades human complement attack by secretion of aspartic proteases. Mol. Immunol. 2009, 47, 465-475. [CrossRef] [PubMed]

5. Poltermann, S.; Kunert, A.; von der Heide, M.; Eck, R.; Hartmann, A.; Zipfel, P.F. Gpm1p is a factor h-, fhl-1-, and plasminogenbinding surface protein of candida albicans. J. Biol. Chem. 2007, 282, 37537-37544. [CrossRef] [PubMed]

6. Luo, S.; Poltermann, S.; Kunert, A.; Rupp, S.; Zipfel, P.F. Immune evasion of the human pathogenic yeast candida albicans: Pra1 is a factor $\mathrm{h}$, fhl-1 and plasminogen binding surface protein. Mol. Immunol. 2009, 47, 541-550. [CrossRef] [PubMed]

7. Lesiak-Markowicz, I.; Vogl, G.; Schwarzmuller, T.; Speth, C.; Lass-Florl, C.; Dierich, M.P.; Kuchler, K.; Wurzner, R. Candida albicans hgt1p, a multifunctional evasion molecule: Complement inhibitor, cr3 analogue, and human immunodeficiency virusbinding molecule. J. Infect. Dis. 2011, 204, 802-809. [CrossRef]

8. Luo, S.; Hoffmann, R.; Skerka, C.; Zipfel, P.F. Glycerol-3-phosphate dehydrogenase 2 is a novel factor h-, factor h-like protein 1-, and plasminogen-binding surface protein of candida albicans. J. Infect. Dis. 2013, 207, 594-603. [CrossRef]

9. Harpf, V.; Rambach, G.; Wurzner, R.; Lass-Florl, C.; Speth, C. Candida and complement: New aspects in an old battle. Front. Immunol. 2020, 11, 1471. [CrossRef]

10. Speth, C.; Rambach, G.; Lass-Florl, C.; Dierich, M.P.; Wurzner, R. The role of complement in invasive fungal infections. Mycoses 2004, 47, 93-103. [CrossRef]

11. American Diabetes, A. 2. Classification and diagnosis of diabetes: Standards of medical care in diabetes-2018. Diabetes Care 2018, 41, S13-S27. [CrossRef] [PubMed]

12. Saeedi, P.; Petersohn, I.; Salpea, P.; Malanda, B.; Karuranga, S.; Unwin, N.; Colagiuri, S.; Guariguata, L.; Motala, A.A.; Ogurtsova, K.; et al. Global and regional diabetes prevalence estimates for 2019 and projections for 2030 and 2045 : Results from the international diabetes federation diabetes atlas, 9(th) edition. Diabetes Res. Clin. Pract. 2019, 157, 107843. [CrossRef] [PubMed]

13. Calvet, H.M.; Yoshikawa, T.T. Infections in diabetes. Infect Dis. Clin. N. Am. 2001, 15, 407-421. [CrossRef]

14. Kenno, S.; Speth, C.; Rambach, G.; Binder, U.; Chatterjee, S.; Caramalho, R.; Haas, H.; Lass-Florl, C.; Shaughnessy, J.; Ram, S.; et al. Candida albicans factor $\mathrm{h}$ binding molecule hgt1p-A low glucose-induced transmembrane protein is trafficked to the cell wall and impairs phagocytosis and killing by human neutrophils. Front. Microbiol. 2018, 9, 3319. [CrossRef] [PubMed]

15. Farah, C.S.; Elahi, S.; Pang, G.; Gotjamanos, T.; Seymour, G.J.; Clancy, R.L.; Ashman, R.B. T cells augment monocyte and neutrophil function in host resistance against oropharyngeal candidiasis. Infect Immun. 2001, 69, 6110-6118. [CrossRef]

16. Fulurija, A.; Ashman, R.B.; Papadimitriou, J.M. Neutrophil depletion increases susceptibility to systemic and vaginal candidiasis in mice, and reveals differences between brain and kidney in mechanisms of host resistance. Microbiology 1996, 142 Pt 12, 3487-3496. [CrossRef] 
17. de Souza Ferreira, C.; Araujo, T.H.; Angelo, M.L.; Pennacchi, P.C.; Okada, S.S.; de Araujo Paula, F.B.; Migliorini, S.; Rodrigues, M.R. Neutrophil dysfunction induced by hyperglycemia: Modulation of myeloperoxidase activity. Cell Biochem. Funct. 2012, 30, 604-610. [CrossRef]

18. Meri, T.; Hartmann, A.; Lenk, D.; Eck, R.; Wurzner, R.; Hellwage, J.; Meri, S.; Zipfel, P.F. The yeast candida albicans binds complement regulators factor $\mathrm{h}$ and fhl-1. Infect Immun. 2002, 70, 5185-5192. [CrossRef]

19. Koehler, P.; Stecher, M.; Cornely, O.A.; Koehler, D.; Vehreschild, M.; Bohlius, J.; Wisplinghoff, H.; Vehreschild, J.J. Morbidity and mortality of candidaemia in europe: An epidemiologic meta-analysis. Clin. Microbiol. Infect. 2019, 25, 1200-1212. [CrossRef]

20. Jafar, N.; Edriss, H.; Nugent, K. The effect of short-term hyperglycemia on the innate immune system. Am. J. Med. Sci. 2016, 351, 201-211. [CrossRef]

21. Kjersem, H.; Hilsted, J.; Madsbad, S.; Wandall, J.H.; Johansen, K.S.; Borregaard, N. Polymorphonuclear leucocyte dysfunction during short term metabolic changes from normo- to hyperglycemia in type 1 (insulin dependent) diabetic patients. Infection 1988, 16, 215-221. [CrossRef] [PubMed]

22. van Oss, C.J.; Border, J.R. Influence of intermittent hyperglycemic glucose levels on the phagocytosis of microorganisms by human granulocytes in vitro. Immunol. Commun. 1978, 7, 669-676. [CrossRef] [PubMed]

23. Jialal, I.; Polage, C.; Devaraj, S. Severe hyperglycemia down regulates toll-like receptors on neutrophils: Implications for propensity to infections in diabetics. FASEB J. 2013, 27, 648.11. [CrossRef]

24. Bassyouni, R.H.; Wegdan, A.A.; Abdelmoneim, A.; Said, W.; AboElnaga, F. Phospholipase and aspartyl proteinase activities of candida species causing vulvovaginal candidiasis in patients with type 2 diabetes mellitus. J. Microbiol. Biotechnol. 2015, 25, 1734-1741. [CrossRef]

25. Rodaki, A.; Bohovych, I.M.; Enjalbert, B.; Young, T.; Odds, F.C.; Gow, N.A.; Brown, A.J. Glucose promotes stress resistance in the fungal pathogen candida albicans. Mol. Biol. Cell 2009, 20, 4845-4855. [CrossRef] [PubMed]

26. Hostetter, M.K. Handicaps to host defense. Effects of hyperglycemia on c3 and candida albicans. Diabetes 1990, 39, 271-275. [CrossRef]

27. Hair, P.S.; Echague, C.G.; Rohn, R.D.; Krishna, N.K.; Nyalwidhe, J.O.; Cunnion, K.M. Hyperglycemic conditions inhibit c3mediated immunologic control of staphylococcus aureus. J. Transl. Med. 2012, 10, 35. [CrossRef]

28. Blom, A.M.; Hallstrom, T.; Riesbeck, K. Complement evasion strategies of pathogens-acquisition of inhibitors and beyond. Mol. Immunol. 2009, 46, 2808-2817. [CrossRef]

29. Ermert, D.; Niemiec, M.J.; Rohm, M.; Glenthoj, A.; Borregaard, N.; Urban, C.F. Candida albicans escapes from mouse neutrophils J. Leukoc. Biol. 2013, 94, 223-236. [CrossRef]

30. Mencacci, A.; Romani, L.; Mosci, P.; Cenci, E.; Tonnetti, L.; Vecchiarelli, A.; Bistoni, F. Low-dose streptozotocin-induced diabetes in mice. Ii. Susceptibility to candida albicans infection correlates with the induction of a biased th2-like antifungal response. Cell Immunol. 1993, 150, 36-44. [CrossRef]

31. Venturini, J.; Fraga-Silva, T.F.; Marchetti, C.M.; Mimura, L.A.; Conti, B.J.; Golim Mde, A.; Mendes, R.P.; de Arruda, M.S Imbalanced macrophage and dendritic cell activations in response to candida albicans in a murine model of diabetes mellitus. Immunol. Investig. 2016, 45, 420-438. [CrossRef] [PubMed]

32. Khan, M.A.; Aldebasi, Y.H.; Alsuhaibani, S.A.; AlSahli, M.A.; Alzohairy, M.A.; Khan, A.; Younus, H. Therapeutic potential of thymoquinone liposomes against the systemic infection of candida albicans in diabetic mice. PLoS ONE 2018, 13, e0208951.

33. Sasada, M.; Johnston, R.B., Jr. Macrophage microbicidal activity. Correlation between phagocytosis-associated oxidative metabolism and the killing of candida by macrophages. J. Exp. Med. 1980, 152, 85-98. [CrossRef]

34. Reeves, E.P.; Lu, H.; Jacobs, H.L.; Messina, C.G.; Bolsover, S.; Gabella, G.; Potma, E.O.; Warley, A.; Roes, J.; Segal, A.W. Killing activity of neutrophils is mediated through activation of proteases by k+ flux. Nature 2002, 416, 291-297. [CrossRef] [PubMed]

35. Tsoni, S.V.; Kerrigan, A.M.; Marakalala, M.J.; Srinivasan, N.; Duffield, M.; Taylor, P.R.; Botto, M.; Steele, C.; Brown, G.D. Complement c3 plays an essential role in the control of opportunistic fungal infections. Infect. Immun. 2009, 77, 3679-3685. [CrossRef] [PubMed]

36. Huber-Lang, M.; Sarma, J.V.; Zetoune, F.S.; Rittirsch, D.; Neff, T.A.; McGuire, S.R.; Lambris, J.D.; Warner, R.L.; Flierl, M.A.; Hoesel, L.M.; et al. Generation of c5a in the absence of c3: A new complement activation pathway. Nat. Med. 2006, 12, 682-687. [CrossRef] [PubMed]

37. Nilsson, P.H.; Johnson, C.; Quach, Q.H.; Macpherson, A.; Durrant, O.; Pischke, S.E.; Fure, H.; Landsem, A.; Bergseth, G.; Schjalm, C.; et al. A conformational change of complement c5 is required for thrombin-mediated cleavage, revealed by a novel ex vivo human whole blood model preserving full thrombin activity. J. Immunol. 2021, 207, 1641-1651. [CrossRef] [PubMed]

38. DiScipio, R.G.D.; Daffern, P.J.D.; Schraufstätter, I.U.; Sriramarao, P. Human polymorphonuclear leukocytes adhere to complement factor $\mathrm{h}$ through an interaction that involves amb2 (cd11b/cd18). J. Immunol. 1998, 160, 4057-4066.

39. Losse, J.; Zipfel, P.F.; Jozsi, M. Factor h and factor h-related protein 1 bind to human neutrophils via complement receptor 3 , mediate attachment to candida albicans, and enhance neutrophil antimicrobial activity. J. Immunol. 2010, 184, 912-921. [CrossRef]

40. Soloviev, D.A.; Jawhara, S.; Fonzi, W.A. Regulation of innate immune response to candida albicans infections by alphambeta2pra1p interaction. Infect. Immun. 2011, 79, 1546-1558. [CrossRef]

41. Chauhan, N.; Kruppa, M.D. Standard growth media and common techniques for use with candida albicans. Methods Mol. Biol. 2009, 499, 197-201. 
42. Subcommittee on Antifungal Susceptibility Testing (AFST) of the ESCMID European Committee for Antimicrobial Susceptibility Testing (EUCAST). Eucast definitive document edef 7.1: Method for the determination of broth dilution mics of antifungal agents for fermentative yeasts. Clin. Microbiol. Infect. 2008, 14, 398-405. [CrossRef]

43. Claudino, A.L.R.; Peixoto, R.F.; Melhem, M.S.C.; Szeszs, M.W.; Lyon, J.P.; Chavasco, J.K.; Franco, M.C. Correlation between clsi, eucast and etest methodologies for amphotericin $\mathrm{b}$ and fluconazole antifungal susceptibility testing of candida spp. Clinical isolates. Pharmazie 2008, 63, 286-289.

44. Clinical and Laboratory Standards Institute. CLSI document M27: Reference method for broth dilution antifungal susceptibility testing of yeasts. In Clinical and Laboratory Standards Institute (CLSI), 4th ed.; Clinical and Laboratory Standards Institute: Wayne, PA, USA, 2017.

45. Noble, S.M.; Johnson, A.D. Strains and strategies for large-scale gene deletion studies of the diploid human fungal pathogen candida albicans. Eukaryot Cell 2005, 4, 298-309. [CrossRef]

46. Rambach, G.; Fleischer, V.; Harpf, V.; Lackner, M.; Meinitzer, A.; Maier, H.; Engesser, J.; Lass-Florl, C.; Speth, C. Comparative immunopathogenesis in a murine model of inhalative infection with the mucormycetes lichtheimia corymbifera and rhizopus arrhizus. PLoS ONE 2020, 15, e0234063. [CrossRef]

47. Janssen, B.J.; De Celle, T.; Debets, J.J.; Brouns, A.E.; Callahan, M.F.; Smith, T.L. Effects of anesthetics on systemic hemodynamics in mice. Am. J. Physiol. Heart Circ. Physiol. 2004, 287, H1618-H1624. [CrossRef] 